E18-2016-22

Yu. Yamauchi ${ }^{1}$, P. Yu. Apel ${ }^{1,2}$

\title{
ADSORPTION OF ANIONIC SURFACTANT ON POROUS AND NONPOROUS POLYETHYLENE TEREPHTHALATE FILMS
}

Submitted to «Colloid Journal»

\footnotetext{
${ }^{1}$ Joint Institute for Nuclear Research, Dubna

2 Dubna State University, Dubna, Russia
} 
Ямаути Ю., Апель П. Ю.

E18-2016-22

Адсорбция анионного поверхностно-активного вещества

на пористых и непористых полиэтилентерефталатных пленках

Исследована адсорбция анионного поверхностно-активного вещества (ПАВ), додецил дифенилоксид дисульфонат натрия (ДДДН), на трех типах полиэтилентерефталатных (ПЭТФ) подложек из водных растворов с различными концентрациями ПАВ. Для изменения ионной силы растворов в них добавляли нейтральный электролит $(\mathrm{KCl})$. В качестве подложек использовали: 1) исходную ПЭТФ пленку, 2) протравленную непористую пленку, полученную из исходной путем химического травления и обладающую отрицательным зарядом поверхности, 3) протравленные пористые мембраны, изготовленные из исходной пленки путем облучения ускоренными ионами и последующего химического травления. Мембраны имеют отрицательный заряд на внешней плоской поверхности и на внутренних стенках пор. Сравнение показывает, что отрицательный заряд на плоской поверхности оказывает слабое влияние на адсорбцию анионного ПАВ, а адсорбция ДДДН на внутренних стенках пор значительно слабее, чем на плоской поверхности, - даже если радиус пор значительно больше, чем дебаевская длина. Этот эффект «исключения» сильно зависит от ионной силы раствора.

Работа выполнена в Лаборатории ядерных реакций им. Г. Н. Флерова ОИЯИ. Препринт Объединенного института ядерных исследований. Дубна, 2016

Yamauchi Yu., Apel P. Yu.

E18-2016-22 Adsorption of Anionic Surfactant on Porous and Nonporous Polyethylene Terephthalate Films

We study the adsorption of anionic surfactant, sodium dodecyl diphenyloxide disulfonate (SDDD) on three types of polyethylene terephthalate (PET) substrates from aqueous solutions of SDDD of different concentrations. Neutral electrolyte $(\mathrm{KCl})$ was added to the solutions to vary the ionic strength. Three types of substrates were used: 1) original PET film; 2) etched nonporous film, obtained from pristine film by chemical etching and bearing negative charge on the surface; 3 ) etched porous membranes, fabricated from pristine film by ion irradiation and subsequent chemical etching. The membranes have negative charge on the flat surface and on the inner pore walls. The comparison shows that the negative charge on the flat surface has weak effect on adsorption of the anionic surfactant, and the SDDD adsorption on the inner walls of pores is much weaker than on flat surface, even if the pore radius is significantly larger than the Debye length. This "exclusion" effect strongly depends on ionic strength of solution.

The investigation has been performed at the Flerov Laboratory of Nuclear Reactions, JINR.

Preprint of the Joint Institute for Nuclear Research. Dubna, 2016 


\section{INTRODUCTION}

The mechanisms of track evolution during chemical treatment are the subject of intensive research that is aimed at the development of nano- and microstructures with pre-determined characteristics [1]. Nano- and micropores of controlled size and shape are important for a variety of applications, such as micro- and ultrafiltration membranes, molecular sensors, optical filters, the template synthesis of nanotubes and nanowires, nano- and microfluidics, and others [2]. The use of surfactants enables one to produce track-etched membranes (TMs) with improved flow rate characteristics compared with those having cylindrical pores of the same nominal pore diameter. Furthermore, incorporating the surfactants provides control over the pore shape in TMs, thus, optimizing their retention and permeation properties [3].

When etching, the surfactant molecules form a quasi-solid adsorption layer, which partially protects the surface from chemical attack and leads to a reduction in the bulk etch rate of the solid. In general, this protective effect depends on the alkali concentration, temperature and type of surfactant. Surfactants with a larger molecular length provide a stronger reduction in etch rate, and the protective effect of surfactants decreases at higher temperatures. The effect of a surfactant on the etching of pores in ion-irradiated polymer foils was studied in [1,3]. It has been suggested that a plug forms at the pore neck, which becomes impermeable to large molecules. The resulting pore profile depends on the rate of etching, the etching time, and the size of the surfactant molecules. In other words, the interplay of diffusion, adsorption, protection, and dissolution determines the evolution of the etched pore channel. The hindered diffusion of surfactants into restricted volumes seems to be a key factor in the formation of track-etched pores that are tapered towards the surface. The present study is aimed at gaining further understanding of the interaction between surfactant molecules and a porous matrix filled with an electrolyte solution. It is known that polyethylene terephthalate (PET) acquires a negatively charged surface due to carboxylic groups created by chemical etching [4]. The density of surface charges has been determined to be equal to approximately 0.5 elementary charges per square nanometer $[5,6]$. Thus, we expect that a nonionic surfactant, which has an electrically neutral hydrophilic head, and an anionic surfactant with a negatively charged hydrophilic head may adsorb differently on the negatively charged PET surface. We also expect that the electrolyte concentration can strongly influence the interaction between the 
anionic surfactant molecule and the chemically etched PET surface due to the screening of electric charges.

The adsorption of ionic surfactants in pores of polycarbonate track-etched membranes has already been studied. It has been shown that both cationic and anionic surfactants are able to adsorb in the pores and alter the pore-wall surface properties, namely, the $\zeta$-potential $[7,8]$. The counter-ion surfactant actively adsorbs within pores creating a monolayer near the critical micelle concentration (CMC) and a bilayer above the CMC. In contrast, the co-ion surfactant is unable to provide sufficient coverage of surface because of the electrostatic repulsion between the surface carboxylate groups and the negatively charged ions of surfactant. To our knowledge, surfactant adsorption on track-etched membranes of polyethylene terephthalate (PET) has never been studied in detail. The electrokinetic properties of PET track membranes were investigated after the sorption of different surfactants and a subsequent rinsing in water [9]. The observed alterations in surface charge were found to be unstable over time, which indicated a gradual desorption of the surfactant, especially anionic, from the pore walls.

In this paper, we use sodium dodecyl diphenyloxide disulfonate (SDDD) as an anionic surfactant to study adsorption on different PET substrates with different electrolyte concentrations. We compare three types of PET substrates: an original film, an etched nonporous film, and an etched porous film. The comparison of two nonporous films - original and nonetched - is expected to show the effect of a negatively charged flat surface on the adsorption of surfactant. The comparison of etched porous and etched nonporous films is aimed at distinguishing between adsorption on a flat film surface and on inner pore walls. Thus, the influence of the curvature of the charged surface on the adsorption of surfactant molecules can be studied. For this purpose, we employ porous substrates having different pore radii. Additionally, the use of porous films allows us to increase the total surface area and, consequently, the amount of adsorbed substance, which reduces the experimental error. We present our fitting of the experimental data by the Langmuir adsorption model.

\section{EXPERIMENT}

1.1. Polymer Films Characteristics. Polyethylene terephthalate (PET) films with a thickness of $23 \mu \mathrm{m}$ (Hostaphan RNK from Mitsubishi Polyester Films) and with a thickness of 10 and $20 \mu \mathrm{m}$ (of USSR production) were used as pristine substrates. Two types of pre-treatment were applied for pristine PET films to modify their surface and structural properties: the etched nonpore films were prepared from pristine PET films by chemical etching under the conditions of $1 \mathrm{M} \mathrm{NaOH}, 70^{\circ} \mathrm{C}, 7 \mathrm{~min}$. The etching procedure applied to the etched nonporous film provided the removal of a layer approximately $0.025 \mu \mathrm{m}$ thick from each side of the film. The etched porous films were produced by the track-etched 
membrane manufacturing process [10], i.e., PET films were first irradiated with $\mathrm{Kr}$ ions $(250 \mathrm{MeV})$ at the $\mathrm{U} 400$ cyclotron. Then, the films were sensitized by ultraviolet irradiation from a source with its maximum intensity at $310-320 \mathrm{~nm}$. The chemical etching was performed in alkaline aqueous solutions.

The etched porous samples were imaged with a scanning electron microscope (JSM-840, JEOL, Japan). The average pore diameters on the surface and the pore densities were estimated from SEM pictures. The airflow rates were measured at a pressure difference of $0.01 \mathrm{MPa}$. A special computer code allowed us to determine the effective pore diameter $\left(D_{\text {eff }}\right)$ based on the sample surface area, pore density, sample thickness, and airflow rate measured at an arbitrary Knudsen number. The total surface area of $1 \mathrm{~g}$ of a porous sample $\left(S_{t}\right)$ was found as the sum of two flat areas of film surface $\left(S_{f}\right)$ and the area of inner pore walls $\left(S_{p}\right)$ for $1 \mathrm{~g}$ of the film. $S_{p}$ was calculated as

$$
S_{p}=D_{\text {eff }} \times \pi \times N \times\left(S_{f} / 2\right) \times L .
$$

Characteristics of original, etched nonporous, and etched porous films are shown in Table 1. We show the thicknesses of the etched films $(L)$, the effective pore diameters $\left(D_{\text {eff }}\right)$, pore densities $(N)$, and the surface areas. The pore channels in the prepared etched porous samples were different in shape. In the case of noncylindrical pores, $D_{\text {eff }}$ means the diameter of a cylindrical pore with the same airflow rate.

Figure 1 shows SEM images of membranes A-D and the sketches of cross section for membranes A and B. Membrane A was etched in a surfactant-doped etchant. As a result, cigar-like pore channels were formed. Average pore diameter on the surface was approximately $0.2 \mu \mathrm{m}$, while the inner pore diameter was larger. This is quite a common pore configuration in membranes of this type [1]. The value of $D_{\text {eff }}(0.28 \mu \mathrm{m}$ for membrane A) constitutes an estimate of the

Table 1. Characteristics of the original, etched nonporous, and etched porous films (membranes A, B, C, and D)

\begin{tabular}{|l|c|c|c|c|c|c|}
\hline \multirow{2}{*}{ Film } & \multirow{2}{*}{$\begin{array}{c}\text { Thickness, } \\
\mu \mathrm{m}\end{array}$} & $\begin{array}{c}\text { Effective } \\
\text { pore } \\
\text { diameter, } \\
\end{array}$ & & \multirow{2}{*}{$\begin{array}{c}\text { Pore } \\
\text { density, } \\
\mathrm{cm}^{-2}\end{array}$} & \multicolumn{3}{|c|}{ Specific surface } \\
\cline { 5 - 7 } & & $\begin{array}{c}\text { Flat } \\
\text { anrface }\end{array}$ & $\begin{array}{c}\text { Pore } \\
\text { walls }\end{array}$ & Total \\
\hline Original & 23 & - & - & 0.0601 & - & 0.0601 \\
\hline Etched nonporous & 10 & - & - & 0.145 & - & 0.145 \\
\hline Membrane A & 20 & 0.28 & $2.8 \cdot 10^{8}$ & 0.098 & 2.41 & 2.51 \\
\hline Membrane B & 20 & 0.26 & $4.8 \cdot 10^{8}$ & 0.101 & 4.00 & 4.10 \\
\hline Membrane C & 20 & 0.48 & $1.6 \cdot 10^{8}$ & 0.103 & 2.46 & 2.56 \\
\hline Membrane D & 22 & 1.02 & $1.0 \cdot 10^{7}$ & 0.072 & 0.218 & 0.290 \\
\hline
\end{tabular}



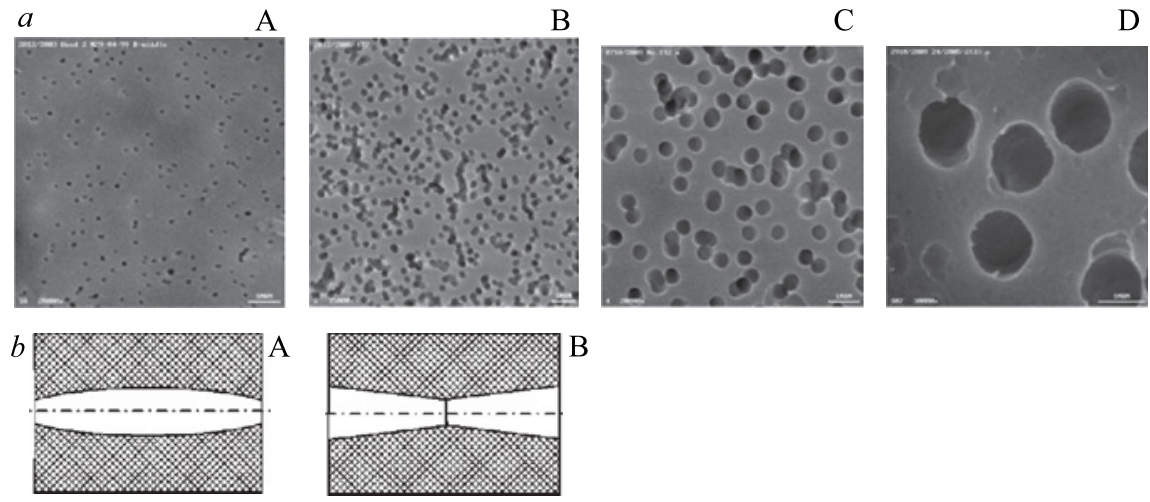

Fig. 1. a) SEM images of membranes A, B, C, and D. Scale bars: $1 \mu \mathrm{m}$. b) Sketches of cross section for membranes A and B

diameter averaged over the pore length. The $D_{\text {eff }}$ can be used to calculate the area of the pore wall surface. In contrast, the pores in membranes B, C, and D were etched using a surfactant-free alkaline solution. Because of a high trackto-bulk etch rate ratio, the channels were almost cylindrical in shape, which is evidenced by the fact that their surface pore diameters coincide with the effective pore diameters within an experimental error of approximately $\pm 5 \%$. As seen from Fig. 1, the surface pore diameter in membrane B is markedly larger than that in membrane A. At the same time, the effective pore diameter is practically the same, which means that single pore channels in these membrane samples have almost identical area of wall surface.

1.2. Surfactant Characterization. Adsorption experiments were performed with the anionic surfactant Dowfax 2A1 (Dow Chemicals), which is an aqueous $50 \%$ solution of sodium dodecyl diphenyloxide disulfonate (SDDD). The molecular weight of SDDD is 541.6. Its molecular structure is shown in Fig. 2. The molar absorption coefficient of SDDD is $(15.64 \pm 0.16) \cdot 10^{3} \mathrm{~L} / \mathrm{mol} \cdot \mathrm{cm}$ at $\lambda=238 \mathrm{~nm}$. It was found by fitting the experimentally measured optical absorbance as a function of concentration in Fig. 3. The CMC in $0.1 \mathrm{M} \mathrm{NaCl}$ at $25^{\circ} \mathrm{C}$ is $0.007 \mathrm{~g} / 100 \mathrm{~g}$ water $(0.1292 \mathrm{mmol} / \mathrm{L})$ [11].

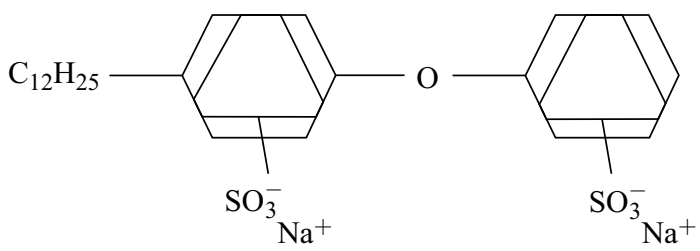

Fig. 2. Chemical formula of sodium dodecyl diphenyloxide disulfonate (SDDD) 


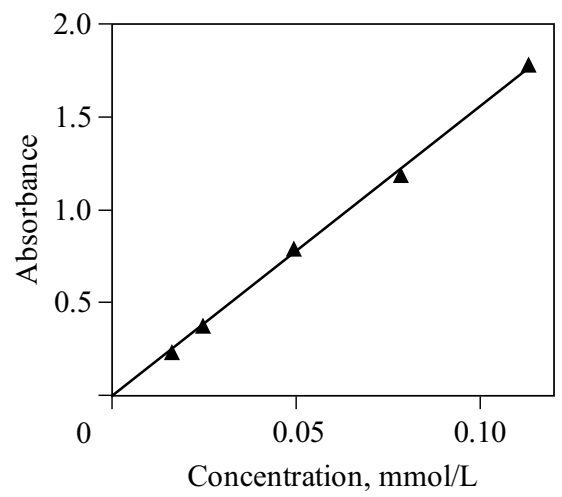

Fig. 3. Calibration plot used for the determination of the molar absorption coefficient of SDDD

1.3. Adsorption Measurements. Several solutions of SDDD with a gradual decrease in concentration were prepared with deionized water. To increase the ionic strength, we added different quantities of the electrolyte, potassium chloride $(\mathrm{KCl})$, to some solutions of SDDD.

Each sample was prepared in the following way. The PET film was cut into small pieces of $2-3 \mathrm{~cm}^{2}$ area. The pieces of PET film were washed 3 times with $50 \mathrm{~mL}$ of deionized water (total $150 \mathrm{~mL}$ ). It has been confirmed that the three-time washing was enough to remove impurities that absorb in the range of 220-330 nm. The SDDD solution $(20 \mathrm{~mL})$ and washed PET film were put into the beaker. The beaker was shaken with a frequency of $40 \mathrm{~min}^{-1}$ for $24 \mathrm{~h}$ to reach the equilibrium adsorption. The resulting solutions were put into quartz cells with a thickness of $1 \mathrm{~cm}$. Optical absorption spectra were measured using a Specord M40 spectrophotometer (Carl Zeiss Jena, Germany) in the range of 220-310 nm. The concentration of the surfactant was determined from the absorbance at $\lambda=238 \mathrm{~nm}$. We calculated the amount of adsorbed surfactant on the PET films from the difference in concentration between the initial solution and the equilibrium solution. Usually, three samples were prepared under identical experimental conditions.

\section{RESULTS}

2.1. Dependence of Adsorption on the Electrolyte Concentration. Let us first present the results of the adsorption of SDDD on the original film. Figure 4, $a$ demonstrates the effect of the electrolyte $\mathrm{KCl}$ concentration on the adsorption isotherm as a function of the SDDD concentration in the solution. In Fig. 4, $b$, we show the average area occupied by an SDDD molecule on the film surface. The area for one molecule of SDDD attains a value of $1 \mathrm{~nm}^{2}$ at high concentrations 

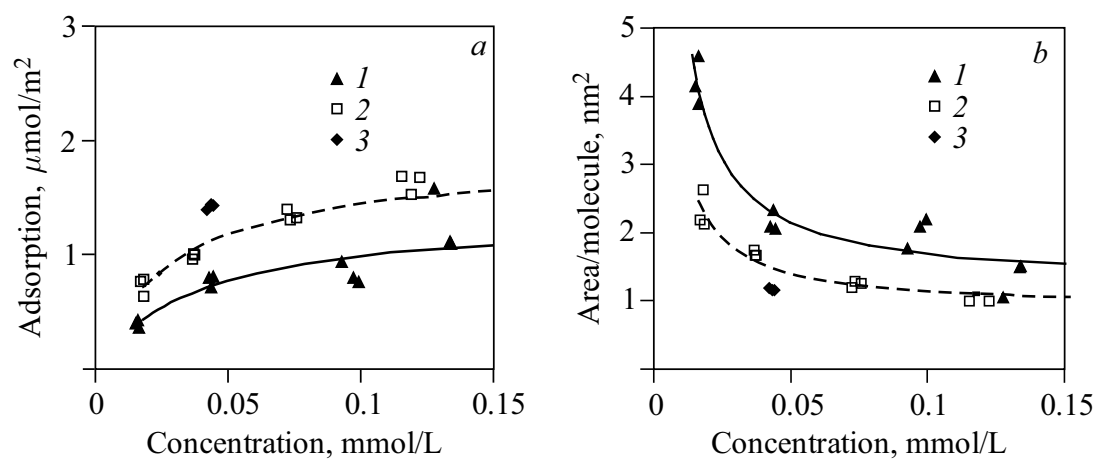

Fig. 4. a) Adsorption isotherms of SDDD on the original film. b) Average area occupied by an SDDD molecule on the original film, as a function of the surfactant concentration at three different concentrations of the electrolyte in aqueous solutions: (1) $0 \mathrm{M} \mathrm{KCl}$, (2) $0.1 \mathrm{M} \mathrm{KCl}$, and (3) $1.0 \mathrm{M} \mathrm{KCl}$. The lines show the fitting of the experimental data by the Langmuir adsorption model

of the surfactant and the electrolyte. Thus, the adsorption layer of SDDD is not as dense as the adsorption layer formed by the nonionic surfactant nonylphenyl decaethylene glycol (the area for one molecule is $0.5 \mathrm{~nm}^{2}$ ) [1]. The negatively charged sulfonate groups disturb the hydrophobic interaction between the PET surface and the surfactant. The increased concentration of $\mathrm{KCl}$ leads to the higher adsorption of SDDD on the film because counter ions $\left(\mathrm{K}^{+}\right)$suppress the repulsion between sulfonate groups of neighboring adsorbed surfactant molecules. Based on the nature of anionic surfactants $[12,13]$ and the existing data in literature $[14,15]$, one should expect this result. Small-angle neutron scattering measurements have shown a remarkable enlargement of SDDD micelles with increasing electrolyte concentration [16]. The growth of micelles and the formation of denser adsorption layers are both a direct result of the suppression of electrostatic repulsion, so that the hydrophobic interaction manifests itself in the aggregation of surfactant molecules to a greater degree.

The effect of the electrolyte $\mathrm{KCl}$ concentration on the adsorption isotherm as a function of the SDDD concentration on the etched nonporous film is presented in Fig. 5, $a$. Similar to the case of the original film, the increased concentration of $\mathrm{KCl}$ leads to the higher adsorption of SDDD. Figure 5, $b$ presents the average area occupied by an SDDD molecule on the etched nonporous film. Although the surface of the etched film has a higher negative charge than that of the original film, its adsorption isotherms are quite close to each other; this shows that the electrostatic repulsion between the carboxylic groups on the PET surface and the hydrophilic heads of the surfactant do not prevent adsorption events. At the same time, the difference between adsorption in $0 \mathrm{M} \mathrm{KCl}$ and in $0.1 \mathrm{M} \mathrm{KCl}$ solutions is larger in the case of the etched film. This indicates that the interaction between 

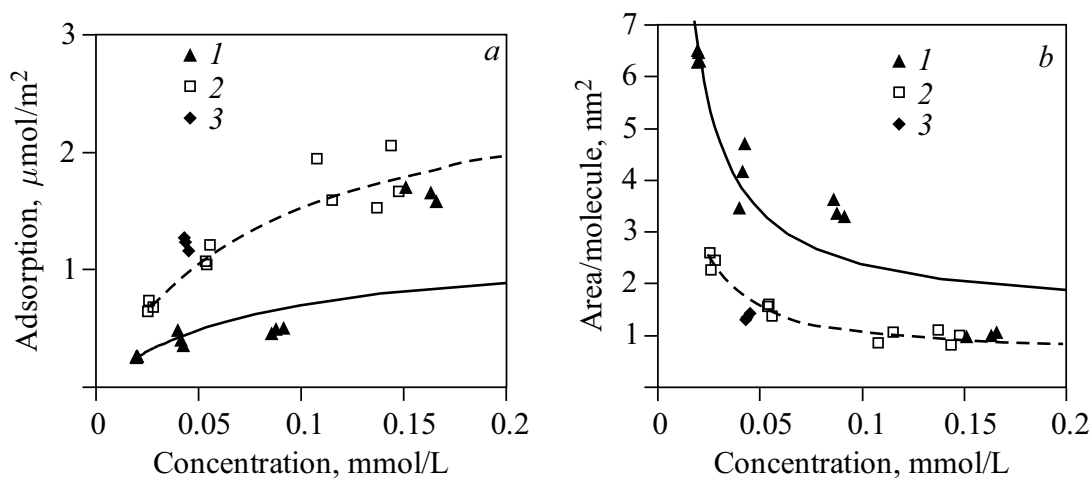

Fig. 5. a) Adsorption isotherms of SDDD on the etched nonporous film. $b$ ) Average area occupied by an SDDD molecule on the etched nonporous film, as a function of the surfactant concentration at three different concentrations of the electrolyte in aqueous solutions: (1) $0 \mathrm{M} \mathrm{KCl}$, (2) $0.1 \mathrm{M} \mathrm{KCl}$, and (3) $1.0 \mathrm{M} \mathrm{KCl}$. The lines show the fitting of the experimental data by the Langmuir adsorption model

surface carboxylic groups and the sulfonate groups of SDDD plays a certain role in decreasing adsorption in the absence of electrolyte.

Figure 6, $a$ presents the influence of the electrolyte $\mathrm{KCl}$ concentration on the adsorption isotherm of SDDD on the surface of an etched porous film (membrane $\mathrm{B}$ ). We observe a strong effect: the increase in the concentration of $\mathrm{KCl}$ leads to a significant increase in the adsorption of SDDD. We found that there
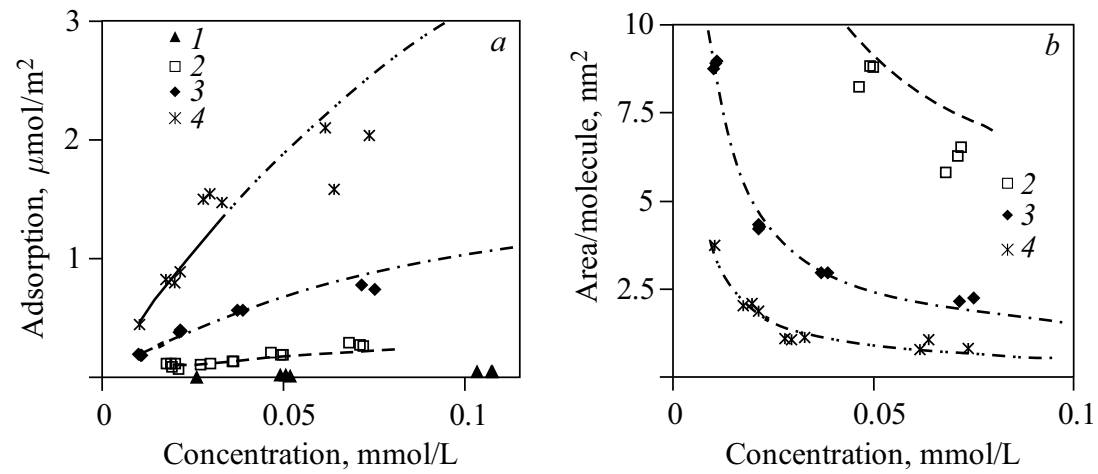

Fig. 6. a) Adsorption isotherms of SDDD on the etched porous film (membrane B). b) Average area occupied by the SDDD molecule on the etched porous film (membrane B), as a function of the surfactant concentration at four different concentrations of the electrolyte in aqueous solutions: (1) $0 \mathrm{M} \mathrm{KCl}$, (2) $0.1 \mathrm{M} \mathrm{KCl,} \mathrm{(3)} 1.0 \mathrm{M} \mathrm{KCl}$, and (4) $3.0 \mathrm{M} \mathrm{KCl}$. The lines show the fitting of the experimental data by the Langmuir adsorption model 
is practically no adsorption within the pores in the absence of the electrolyte at surfactant concentrations below $0.1 \mathrm{mmol} / \mathrm{L}$. Thus, the exclusion effect for coions [17] has a great influence on the adsorption of the doubly charged SDDD anion within negatively charged pores. Figure $6, b$ shows the average area occupied by the SDDD molecule on membrane B as a function of the surfactant concentration in an aqueous solution in the presence of the electrolyte. Here, one has to note that total surface area of membranes mostly represents the pore walls as is seen from Table 1. This is especially true for membrane B. Therefore, the data shown in Fig. 6 illustrate the situation within the pores quite accurately. The surfactant is distributed extremely heterogeneously. Thus, it is mostly on the flat surfaces and less in the pores, especially at low electrolyte concentrations.

2.2. The Results of Data Fitting. The Langmuir adsorption model relates the coverage or adsorption of molecules on a solid surface to the concentration of a medium above the solid surface at a fixed temperature. The equation is stated as

$$
V=K C V_{\max } /(1+K C),
$$

where $V$ is the amount adsorbed; $C$ is the concentration of adsorbing molecules in bulk solution; $K$ is the Langmuir adsorption constant, which increases with an
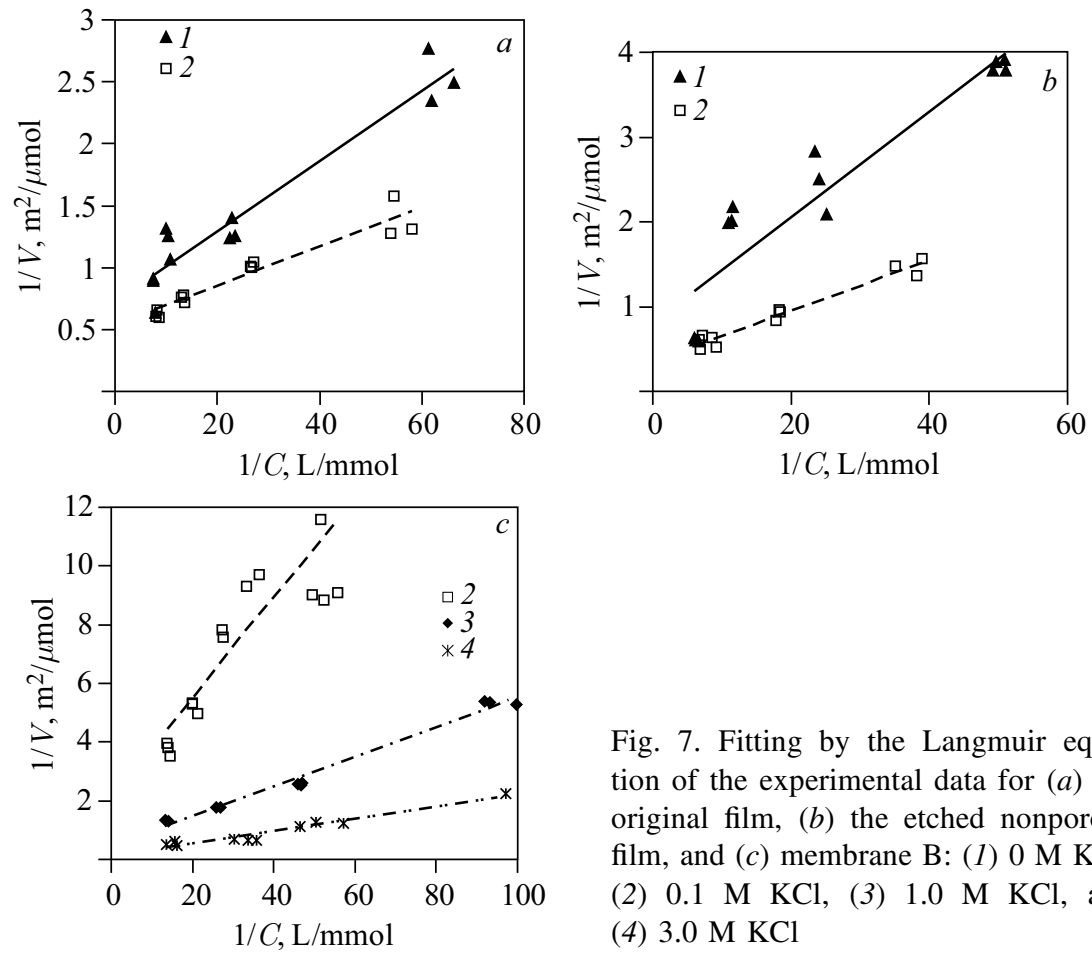

Fig. 7. Fitting by the Langmuir equation of the experimental data for $(a)$ the original film, $(b)$ the etched nonporous film, and (c) membrane B: (1) $0 \mathrm{M} \mathrm{KCl}$, (2) $0.1 \mathrm{M} \mathrm{KCl}$, (3) $1.0 \mathrm{M} \mathrm{KCl}$, and (4) $3.0 \mathrm{M} \mathrm{KCl}$ 
increase in the binding energy of adsorption and with a decrease in temperature; $V_{\max }$ is the maximum amount adsorbed as $C$ increases, i.e., the monolayer saturation capacity. The Langmuir equation can be fitted to data by linear regression or nonlinear regression methods. The double reciprocal of the Langmuir equation is

$$
1 / V=1 / V_{\max }+1 /\left(K C V_{\max }\right) .
$$

A plot of $(1 / V)$ versus $(1 / C)$ in Fig. 7 yields a slope equal to $1 /\left(V_{\max } K\right)$ and an intercept $1 / V_{\max }$. The obtained parameters $V_{\max }$ and $K$ are shown with their tolerance intervals in Table 2.

The errors are quite large, which is partially caused by the specificity of the experimental procedure. It is difficult to accurately measure a small difference in the optical absorbance of two surfactant solutions with a relatively high and almost identical concentration. However, the wide tolerance ranges of the $K$ and $V_{\max }$ values can also result from the fact that the adsorption does not necessarily obey the Langmuir law. The aggregation of surfactant molecules on a substrate surface occurs in a complicated way and strongly depends on whether the CMC has been reached or not [15]. At a $\mathrm{KCl}$ concentration of $3 \mathrm{~mol} / \mathrm{L}$, the $V_{\max }$ value of $8.9 \mu \mathrm{mol} / \mathrm{m}^{2}$ corresponds to an area of $0.2 \mathrm{~nm}^{2}$ per surfactant molecule. This number does not seem to be realistic and is likely caused by the abovementioned reasons. However, at least on a semi-quantitative level, the behavior of parameters $K$ and $V_{\max }$ is consistent and demonstrates that the coverage

Table 2. Parameters for the Langmuir equation calculated from the experimental data for the original, etched nonporous, and etched porous films (membrane B)

\begin{tabular}{|c|c|c|c|c|}
\hline \multirow{2}{*}{ Film, parameter } & \multicolumn{4}{|c|}{ Electrolyte concentration $(\mathrm{KCl})$} \\
\hline & 0 & 0.1 & 1 & 3 \\
\hline $\begin{array}{l}\text { Original film: } \\
K, \mathrm{~L} / \mathrm{mmol} \\
\text { Tolerance range of } K \\
V_{\max }, \mu \mathrm{mol} / \mathrm{m}^{2} \\
\text { Tolerance range of } V_{\max }\end{array}$ & $\begin{array}{c}26 \\
21-32 \\
1.37 \\
1.22-1.57\end{array}$ & $\begin{array}{c}33 \\
28-40 \\
1.89 \\
1.74-2.07\end{array}$ & $\begin{array}{l}- \\
- \\
-\end{array}$ & $\begin{array}{l}- \\
- \\
-\end{array}$ \\
\hline $\begin{array}{l}\text { Etched nonporous film: } \\
K, \mathrm{~L} / \mathrm{mmol} \\
\text { Tolerance range of } K \\
V_{\max }, \mu \mathrm{mol} / \mathrm{m}^{2} \\
\text { Tolerance range of } V_{\max }\end{array}$ & $\begin{array}{c}13 \\
8-19 \\
1.24 \\
0.97-1.72\end{array}$ & $\begin{array}{c}12 \\
10-15 \\
2.8 \\
2.5-3.2\end{array}$ & $\begin{array}{l}- \\
- \\
-\end{array}$ & $\begin{array}{l}- \\
- \\
-\end{array}$ \\
\hline $\begin{array}{l}\text { Etched porous film (membrane } \mathrm{B} \text { ): } \\
K, \mathrm{~L} / \mathrm{mmol} \\
\text { Tolerance range of } K \\
V_{\max }, \mu \mathrm{mol} / \mathrm{m}^{2} \\
\quad \text { Tolerance range of } V_{\max }\end{array}$ & $\begin{array}{l}- \\
- \\
-\end{array}$ & $\begin{array}{c}12 \\
5-23 \\
0.48 \\
0.31-1.06\end{array}$ & $\begin{array}{c}8.8 \\
5.8-12.0 \\
2.3 \\
1.7-3.3\end{array}$ & $\begin{array}{c}5.4 \\
1.3-10.2 \\
8.9 \\
5.1-33.4\end{array}$ \\
\hline
\end{tabular}


of the surface with adsorbed surfactant molecules systematically increases with electrolyte concentration. At high salt concentrations, the formation of a dense adsorption layer also takes place in the pores. The layer is able to weaken chemical attack of the surface in case an aggressive agent is present in the solution.

In the framework of this interpretation, the strong dependence of the shape of track-etched nanopores on the alkali concentration in etchants doped with SDDD $(\sim 1 \mathrm{mmol} / \mathrm{L})$, as reported in [18], is well understood.

2.3. Difference in Adsorption on the Original, Etched Nonporous, and Etched Porous Substrates. Figure 8 shows the adsorption of SDDD on three types of substrates for $0.1 \mathrm{~mol} / \mathrm{L}$ of $\mathrm{KCl}$ concentration, at room temperature. The adsorption was normalized to the total area, including the inner pore walls in

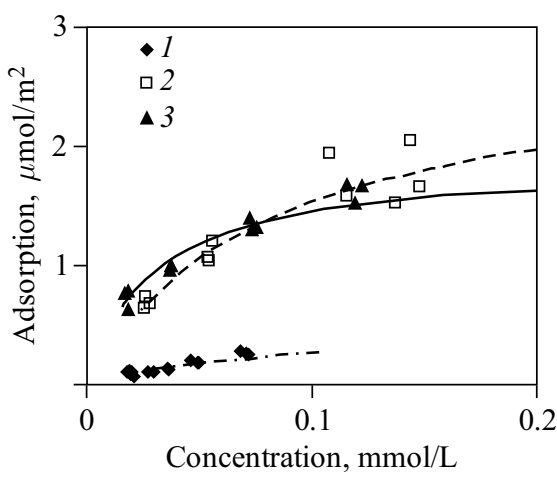

Fig. 8. Adsorption isotherms of SDDD from the aqueous solutions with $0.1 \mathrm{M} \mathrm{KCl}$ onto (1) membrane $\mathrm{B},(2)$ the etched nonporous, and (3) the original films, as a function of the surfactant concentration the case of the etched porous film (membrane B). We can see that the adsorption isotherms for the two nonporous films does not differ much, i.e., the etching does not strongly influence the adsorption of the surfactant. However, there is a difference. The effect of a negative electric charge on the etched surface leads to slightly lower adsorption at low SDDD concentrations in the solution. On the contrary, at higher surfactant concentrations $(>0.1 \mathrm{mmol} / \mathrm{L})$ the adsorption of SDDD on the etched nonporous film appears to be higher than that on the original film. This is probably due to the roughness of the etched surface. Indeed, the rough relief has a larger surface area and can host more surfactant molecules. On the nanometer scale, the etched surface of semicrystalline PET is remarkably rough and therefore possesses a significantly larger effective area [19]. The porous substrate with pores that are $0.26 \mu \mathrm{m}$ in diameter exhibits significantly lower adsorption for the whole range of surfactant concentrations. Note that the surface area of the pore walls accounts for approximately $97 \%$ of the total surface (see Table 1). Therefore, the adsorption inside the pores is much lower than that on the flat surface because the negatively charged pore walls repel the SDDD di-anions. In spite of the fact that the pore radius is much larger than the Debye length (which is approximately $1 \mathrm{~nm}$ at this ionic strength, $0.1 \mathrm{M} \mathrm{KCl}$ ), the charged pores are found to significantly hinder the ability of doubly charged surfactant molecules to penetrate and adsorb inside. On the one hand, this phenomenon seems surprising; 
on the other hand, a very strong suppression of the transport of doubly charged ions through Nuclepore membranes with relatively large pores has been observed before [20] and appears to be directly relevant to our results on the adsorption of SDDD in pores.

2.4. The Effect of Pore Size and Shape. Figure 9 shows the adsorption isotherms of SDDD for the porous substrates with different pore sizes and shapes. All of the isotherms were measured at the same concentration of electrolyte $(0.1 \mathrm{M} \mathrm{KCl})$. The data are characterized by a wide scatter because the adsorption values were often obtained as a relatively small difference between two large numbers, which introduced a large error. However, we can conclude that the two membranes with almost identical effective pore diameters (membranes A and B) behaved differently at low concentrations of surfactant $(<0.05 \mathrm{mmol} / \mathrm{L})$. The membrane with pores tapered towards both ends showed a lower adsorption (triangles in Fig. 9) compared with the membrane with a larger pore opening (squares in Fig. 9). This probably indicates that the narrow pore necks enhance the exclusion effect due to the Coulomb interaction. At higher SDDD concentrations this phenomenon vanishes. For the membranes B, C, and D having cylindri-

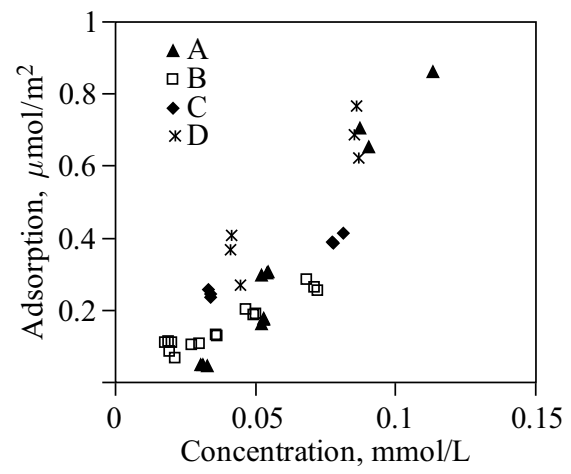

Fig. 9. Adsorption isotherms of SDDD from the aqueous solutions with $0.1 \mathrm{M} \mathrm{KCl}$ onto four etched porous films (membranes $\mathrm{A}, \mathrm{B}, \mathrm{C}$, and D) with different pore sizes and shapes. Their average pore diameters are $0.28,0.26,0.48$, and $1.02 \mu \mathrm{m}$ cal (or slightly doubly conical) pores, the adsorption from diluted SDDD solutions systematically increases with increasing pore radius. The membrane with the largest pores (membrane D, asterisks in Fig. 9) shows the highest adsorption because the exclusion effect is the least pronounced.

\section{CONCLUSIONS AND OUTLOOK}

We studied the diffusion and adsorption of sodium dodecyl diphenyloxide disulfonate on three types of PET substrates: the original film, the etched nonporous film, and the track-etched membranes. Experiments clearly show that adsorption of the anionic surfactant in pores with negatively charged walls is significantly lower than the adsorption on flat surfaces of the original and the etched nonporous films. This phenomenon is caused by the co-ion exclusion effect, which plays a significant role in solutions of low ionic strength. The negatively charged carboxylic groups on the flat surface of etched PET have a 
much weaker effect on the adsorption. It was also shown that the adsorption of anionic surfactants on all three types of substrates (original, etched nonporous, etched porous) significantly increases with increasing electrolyte concentration. The repulsion between the negatively charged sulfonate groups of the surfactant molecules is neutralized by the addition of an electrolyte. As a result, the anionic surfactant forms a denser adsorption layer.

The obtained results are important for a better understanding of the processes of the adsorption and diffusion of ionic species and molecules in nanocapillaries with an electrical charge on the walls. We plan to concentrate future work on the diffusion of anionic surfactants through nanopores. The data on adsorption and diffusion are expected to complement each other, such that a model for surfactant-controlled track etching can be built.

\section{REFERENCES}

1. Apel P. Yu. et al. // Radiat. Meas. 2008. V.43. P. S552.

2. Spohr R. // Radiat. Meas. 2005. V.40. P. 191.

3. Apel P. Yu. et al. // Nucl. Instr. Meth. B. 2001. V. 179, P. 55.

4. Lück H. B. // Nucl. Instr. Meth. 1983. V.213. P. 507.

5. Apel P. Yu., Pretzsch G. // Nucl. Tracks Radiat. Meas. 1986. V.11. P. 45.

6. Geissman C., Ulbricht M. // Macrom. Chem. Phys. 2005. V.206. P. 268.

7. Bisio P. D. et al. // J. Colloid Interface Sci. 1980. V. 78. P. 225.

8. Keesom W. H., Zelenka R.L., Radtke C.J. // J. Colloid Interface Sci. 1988. V. 123. P. 575.

9. Sidorova M. P. et al. // Kolloidnyi zhurnal. 1990. V.52. P. 895 (in Russian). English translation: Colloid journal of the USSR. 1990. V.52. P. 774.

10. Apel P. Yu. // Radiat. Meas. 2001. V.3. P. 559.

11. Dowfax 2A1 Data Sheet. http://www.dow.com/assets/attachments/business/pcm/ dowfax/dowfax_2a1/tds /dowfax_2a1.pdf

12. Attwood D., Florence A.T. // Surfactant Systems. Their Chemistry, Pharmacy and Biology. London: Chapman and Hall, 1983. P. 10.

13. Rusanov A.I. Micelle Formation in Solutions of Surfactants. St. Petersburg: Khimia, 1992 (in Russian).

14. Zhao J., Brown W. // J. Colloid Interface Sci. 1995. V.169. P. 39.

15. Paria S., Khilar K. C. // Adv. Colloid Interface Sci. 2004. V. 110. P. 75.

16. Kovalev Yu.S. et al. // Colloid Journal. 2009. V.71. P. 634.

17. Plecis A., Schoch R. B., Renaud P. // Nano Lett. 2005. V. 5. P. 1147.

18. Apel P. Yu. et al. // Nanotechnology. 2007. V. 18. Art. 305302.7 pp.

19. Olejniczak K., Orelovitch O.L., Apel P. Yu. // Nucl. Instr. Meth. B. 2015. V.365. P. 646.

20. Letant S. E. et al. // Small. 2006. V.2. P. 1504.

Received on March 29, 2016. 


\section{Редактор Е. И. Крупко}

Подписано в печать 08.06.2016.

Формат $60 \times 90 / 16$. Бумага офсетная. Печать офсетная.

Усл. печ. л. 0,81. Уч.-изд. л. 1,20. Тираж 195 экз. Заказ № 58846.

Издательский отдел Объединенного института ядерных исследований 141980 , г. Дубна, Московская обл., ул. Жолио-Кюри, 6.

E-mail: publish@jinr.ru www.jinr.ru/publish/ 